\title{
Development of Medical Record With Extreme Programming SDLC
}

\author{
I Gusti Ngurah Suryantara ${ }^{1}$, Johanes Fernandes Andry ${ }^{2}$ \\ Faculty of Technology and Design, Bunda Mulia University, Jl. Lodan Raya No. 2 Ancol, North Jakarta 14430, \\ Indonesia \\ ${ }^{1}$ gusti@bundamulia.ac.id \\ 2jandry@bundamulia.ac.id
}

Received on February $7^{\text {th }}, 2018$

Accepted on June $8^{\text {th }}, 2018$

\begin{abstract}
The XP model (eXtreme Programming) is used for the development of medical record applications. Because for project development requires rapid adaptation to changes that occur during the development of the application. XP is also suitable for fewer team members and is in the same location. Software development should be well planned, so that the software obtained quality and in accordance with the needs of users. The successful development of this software with XP can be avoided existence of patchwork in application development. Step by step research methods for medical record software are Planning, design, coding, testing and software upgrades. Studies conducted in this study include: literature study, interviews, observation, and document examination. Next do an analysis of the created application, and check the document to get an idea of the system created. This is done as an analysis and system design done by the author. The correct framework at the time of the application development bridge between the developer side and the user side, so that the developed application can be completed on time. XP focuses more on software development and system design with CRC (Classroom Responsibility Collaborator). CRC creators must be thorough and consider CRC interrelationships with each other. The XP framework that every step always involves users, programmers, and parts of the test so that the applications created can be completed in a timely manner and in accordance with the needs of users.
\end{abstract}

Index Terms- CRC (Class Responsibility Collaborator), eXtreme Programming (XP), Medical Record, System.

\section{INTRODUCTION}

Software Development Life Cycle (SDLC) is a strategy of constructing or maintaining software systems [1], [2]. Software methodologies like Waterfall, Vee-Methodology and Rational Unified Process (RUP) are called traditional software development methodologies and these are classified as heavyweight methodologies [1], [3]. Now six techniques that are recognized as agile development strategies, which are: Agile Crystal methodologies, agile dynamic software development methodology, feature-driven development method, lean software development, scrum, extreme programming.[1], [4]

The system developed is very diverse, from desktop applications to web-based applications. Applications developed by application developers, Searching and opening jobs. Like Bill Gates with his Microsoft company, Mark Zuckerberg with Facebook's social network creation, Larry Page and Google's creator Sergy Brin, and still many people who are successful with IT [5]. Most IT companies, even IS businesses are lead by non-technical people. Xtreme Programming (XP) so popular because to develop are software engineering centric [6].

There are some organizational units that require different applications and then developed based on their respective styles and platforms. The thing that will happen is the organization will have some kind of information system that is not integrated. As a result, the leader will be difficult to obtain the information he needs if the information is sourced from various existing information systems [7]. XP breaks down a project into sub-projects, each including planning, development, integration, testing and delivery [4], [8]. They rely on planning, with the understanding that everything is uncertain, to guide the rapid development of flexible systems of high value [4], [8], [9].

$\mathrm{XP}$ is best suited for project development that requires rapid adaptation to changes that occur during application development. XP is also suitable for fewer team members and is in the same location in software development [10]. The selection of appropriate system development frameworks will have a significant impact on software development, so there is no crisis of software.

\section{THEORIES}

\section{A. Analysis and Design System}

In designing the system can use a non object approach and object-oriented [11]. To design system on the framework XP can use CRC (Class Responsibility Collaborator), see Fig 1. 


\begin{tabular}{|ll|}
\hline DOCTOR & \\
\hline Superclasses & $:-$ \\
\hline Subclasses & $:-$ \\
\hline Responsibilities: & Collaborators: \\
\hline -IdDoctor & -Schedule \\
-Name & -Patient \\
-Sex & -Drug \\
-Address & -Cost \\
-Save & \\
-Edit & \\
-Delete & \\
\hline
\end{tabular}

Fig 1. Class Responsibility Collaborator

CRC [10]. In developing the applications, can use the concept of object oriented. The four main points on the concept of object-oriented programming are: Abstraction, Encapsulation, Polymorphism [11].

\section{B. eXtreme Programming $(X P)$}

$\mathrm{XP}$ is a package of several practices and ideas, most of which are not new. The combination and packaging of all of these is, however, new [12], [13]. Extreme Programming was in fact targeted especially at small co-located teams developing non-critical products. It has been suggested that the early adopters of agile methods have been small high-tech product companies [12], [14]. Currently, however, it has already been proven at many companies of all different sizes and industries worldwide [12]. XP provides a list of simple, specific, and seemingly naïve principles and values that guide the software development process throughout the main four phases of software development: planning, coding, designing, and testing.

XP provides a list of simple, specific, and seemingly naïve principles and values that guide the software development process throughout the main four phases of software development: planning, coding, designing, and testing (see Fig 2).

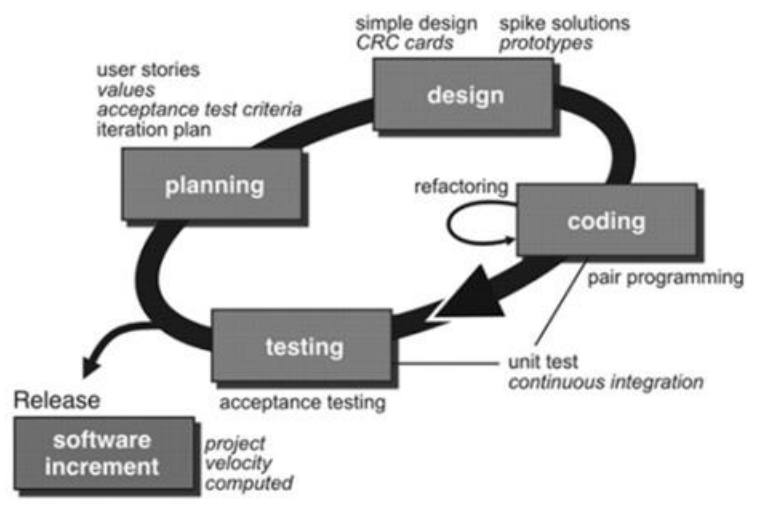

Fig 2. XP Methodology

Software Development Life Cycle is a process to develop software. This process is divided into some phases such asRequirement Analysis, Design, Coding, Testing, Installation and Maintenance. All these activities are carried out in different ways as per the client"s need. Each way is known as a Software Development Life Cycle Model. Every system must go through these phases whether it is small scale or large scale [15], [16], [17].

Planning, at this stage begins with an understanding of the business proceses of the application, defines the output, the features that exist in the application, the functionality of the application created, the timing and cost of application development, and the application development flow. Design, at this stage emphasizes simple application design, tools for designing at this stage can use CRC cards (Class Responsibility Collaborator). CRC is used for mapping classes that will be used in use case diagrams, class diagrams, and object diagrams, Coding, the main thing in developing apliksi using XP is pair programming (in making programs involving two or more programmers). Testing, at this stage focuses on testing the features that exist in the application so that no errors and applications made in accordance with business processes on the client.

Selection of the SDLC framework is Important, because the success of the software can't be separated from the framework. XP provides a paradigm of flexibility between users and developers in accommodating software requirements spesifications to suit the users wishes, and the time required too tight.

\section{Medical Record}

The medical record (MR) by definition is a "collection of data on a patient including a history, statement of current problem, diagnosis and the treatment procedures [18]. MR is referred to as managing patient medical records electronically from a variety of sources. It deals with patient treatment, diagnosis, laboratory test, imaging, history, prescription and allergies that can be accessed from various sites within the organization with the protection of security and patient privacy [19], [20], [21], [22].

\section{RESEARCH METHODS}

XP put more emphasis on software engineering pratices than project management. XP put more emphasis on the engineers than the project managers. The authors argue that XP deserves to be discussed in this paper because some books have not discussed in detail and comprehensive, and its innovation in the development of software. Authors in this paper act is project manager, and do something development, like: step by step of Research Methods see figure 4 . 
From Figure 4 can be seen this research method is divided into five stages according to the XP framework consisting of five parts are:

1. Step I Planning, At this stage on the XP model. Research conducted at the planning stage are: user stories, understanding the business process, defining the output of the application, features In the application, the function of the application, the determination of the time and cost of the application, the flow of application development.

2. Step II Design. The XP methodology emphasizes simple system design, focusing more on programming and program testing. This is because XP takes short time, so with $\mathrm{CRC}$ card is enough to represent the system design in this research.

3. Step III Coding. In the Coding stage, the research included are create a database, Create a program, Create a user guide.

4. Step IV Testing. Testing in software environment with full database.

5. Step V Software Increment. In the software increment stage is a research for the release of applications made to the user.

The contribution of this paper is to generate an blueprint of application development with the XP. XP is different from other SDLC is because XP do mapping in detail and comprehensive.

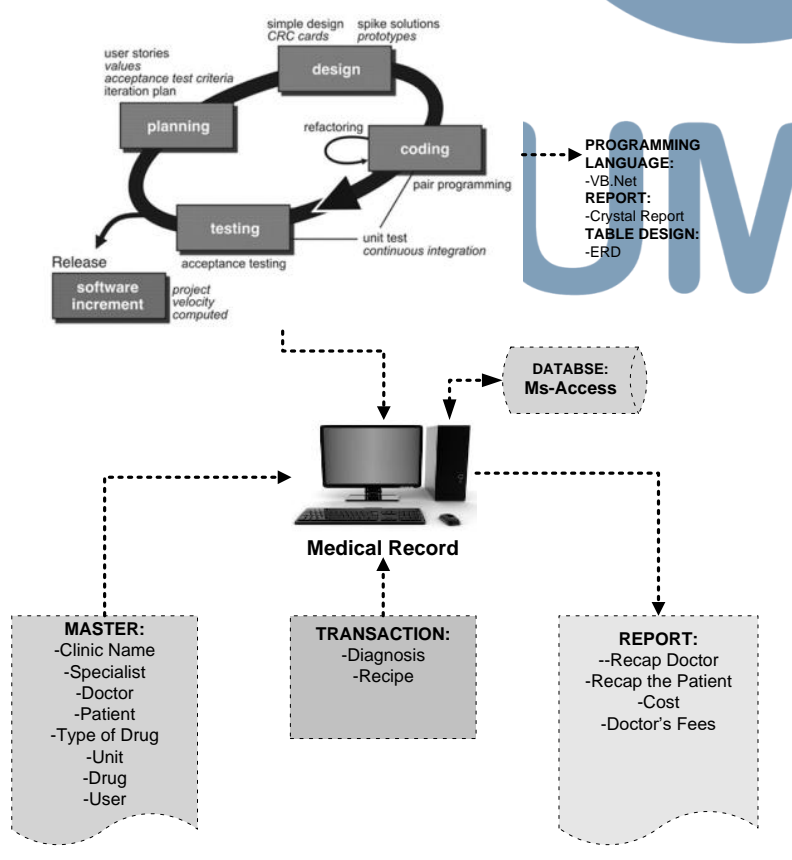

IV. RESUlt AND ANALYSIS

\section{A. Requirement}

Requirement for applications to help today's work is needed, such as computerized medical records applications, personnel and payroll applications, accounting applications, and more.

\section{B. Mapping of Application}

Table 1. Mapping File Master-Report Transaction

\begin{tabular}{|c|l|}
\hline \multicolumn{2}{|c|}{ No } \\
\hline Master File \\
\hline 1 & Clinic Name \\
\hline 2 & Specialist \\
\hline 3 & Doctor \\
\hline 4 & Patient \\
\hline 5 & Type of Drug \\
\hline 6 & Unit \\
\hline 7 & Drug \\
\hline 8 & User \\
\hline Diagnosis & \\
\hline 1 & Diagnosis \\
\hline 2 & Recipe \\
\hline Report & \\
\hline 1 & Recap Doctor \\
\hline 2 & Recap the Patient \\
\hline 3 & Cost \\
\hline 4 & Doctor's Fee \\
\hline
\end{tabular}

Mapping to be used for many details in the applications so that it is easier for project managers to bring agility in to the company. A lot of organization doing right now is just continuous build not continuous integration. The description of the application made in this research is: determine the master file, transaction file, then report file (see table. 1). Mapping of applications include are master file, diagnosis and report..

C. Cycle of Application Medical Record

Cycle of application Medical Record in the application created as in Fig 5.

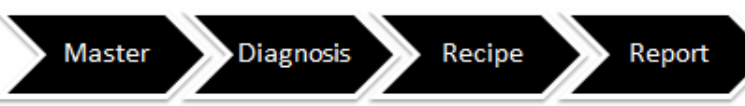

Fig 5. Cycle of Aplications

Included entering master data, the transaction includes the patient's diagnosis by the physician, the admin section copies the prescriptions made by the doctor, and makes the report.

Fig 4. Step by Step of Research Methods 


\section{Schedule Development}

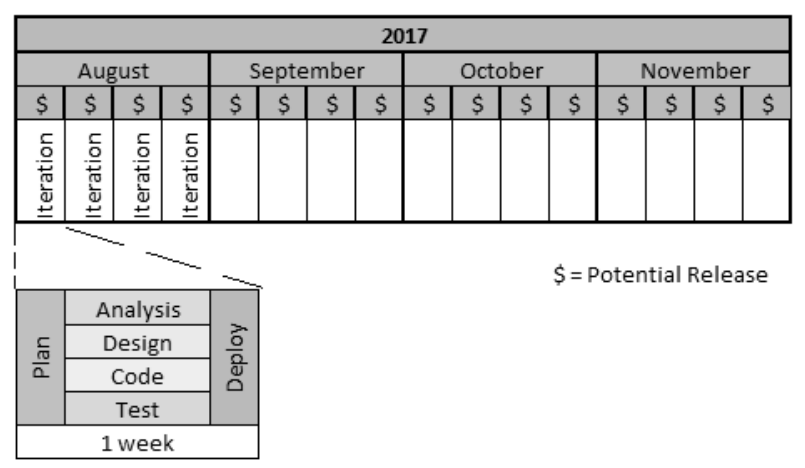

Fig 6. Life Cycle and Schedule Development

To get an overview of the blueprint of medical record application development, the application creation framework is mapped from the selection of system development methodology, system design tools, database used, programming language used, entity connectivity, master file, transaction file, file report. Life cycle and application development schedule with XP methodology as in Fig 6.

\section{E. Planning}

Every activity on application development, developers create documentation. The following documentation Understanding Business Context through user stories.

\section{Table 2. User Stories}

\section{User Stories}

User input master data, such as: Clinic Name, Specialist, Doctor, Patient, Type of Drug, Unit, Drug, Use. Doctor do diagnosed to patiens, Result of diagnosed enter to system (Recipe). Recipes made in the insert into the system. From system can print: Recap Doctor, Recap the Patient, Cost, Doctor's Fee.

Here is the documentation of output mapping on medical record application.

\section{Table 3. Output Application}

\begin{tabular}{|c|l|l|}
\hline No & \multicolumn{1}{|c|}{ Output } & \multicolumn{1}{c|}{ Explanation } \\
\hline 1 & Recap Doctor & Recap and Print Doctor. \\
\hline 2 & Recap the Patient & Recap and Print Patient. \\
\hline 3 & Cost & Recap and Print Drug. \\
\hline 4 & Doctor's Fee & Print cost Doctor. \\
\hline
\end{tabular}

\section{F. Design}

In the design phase, $\mathrm{CRC}$ and Prototype mapping is done, the design of this system using CRC because to create applications with object-oriented kosep. Each $\mathrm{CRC}$ will be a class on the concept of object-oriented programming.

Table 4. Design CRC and Mapping of Class

\begin{tabular}{|l|l|l|}
\hline No & \multicolumn{1}{|c|}{ CRC Design } & \multicolumn{1}{c|}{ Class Mapping } \\
\hline 1 & Login & clsLogin \\
\hline 2 & ClinicClinicName & clsClinicName \\
\hline
\end{tabular}

\begin{tabular}{|l|l|l|}
\hline 3 & Specialist & clsSpecialist \\
\hline 4 & Doctor & clsDoctor \\
\hline 5 & Patient & clsPatient \\
\hline 6 & Type of Drug & clsTypeOfDrug \\
\hline 7 & Unit & clsUnit \\
\hline 8 & Drug & clsDrug \\
\hline 9 & User & clsUser \\
\hline 10 & Diagnosed & clsDiagnosis \\
\hline 11 & Recipe & clsRecipe \\
\hline 12 & RecapDoctor & clsRecapDoctor \\
\hline 13 & Recap the Patient & clsRecapThePatient \\
\hline 14 & Cost & clsCost \\
\hline 15 & Doctor's Fee & clsDoctorFee \\
\hline
\end{tabular}

Example of CRC can see Fig 7.

\begin{tabular}{|c|c|c|c|}
\hline \multicolumn{2}{|c|}{$\begin{array}{l}\text { DOCUMENT } \\
\text { NAME }\end{array}$} & \multicolumn{2}{|l|}{ : DESIGN CRC } \\
\hline \multicolumn{2}{|c|}{ Name of Application } & \multicolumn{2}{|l|}{ Medical Record } \\
\hline \multicolumn{2}{|c|}{ Activities } & \multicolumn{2}{|l|}{ : Design CRC } \\
\hline \multicolumn{2}{|c|}{ During } & \multicolumn{2}{|c|}{ : 11/08/2017 until $20 / 08 / 2017$} \\
\hline No & & CRC & Description \\
\hline \multirow[t]{9}{*}{1} & & & \multirow{9}{*}{$\begin{array}{l}\text { Login CRC can } \\
\text { be modeled into } \\
\text { a class. }\end{array}$} \\
\hline & \multicolumn{2}{|l|}{ LOGIN } & \\
\hline & Superclasses & $:-$ & \\
\hline & Subclasses & $:-$ & \\
\hline & Responsibilitie & s: Collaborators: & \\
\hline & User & clsuser & \\
\hline & Password & & \\
\hline & Login & & \\
\hline & Exit & & \\
\hline & & & etc \\
\hline
\end{tabular}

Fig 7. Mapping of CRC

The mapping of prototype of medical record application in this research is CRC mapping result that has been made on CRC design. In Figure 6 shows a prototype in the application.

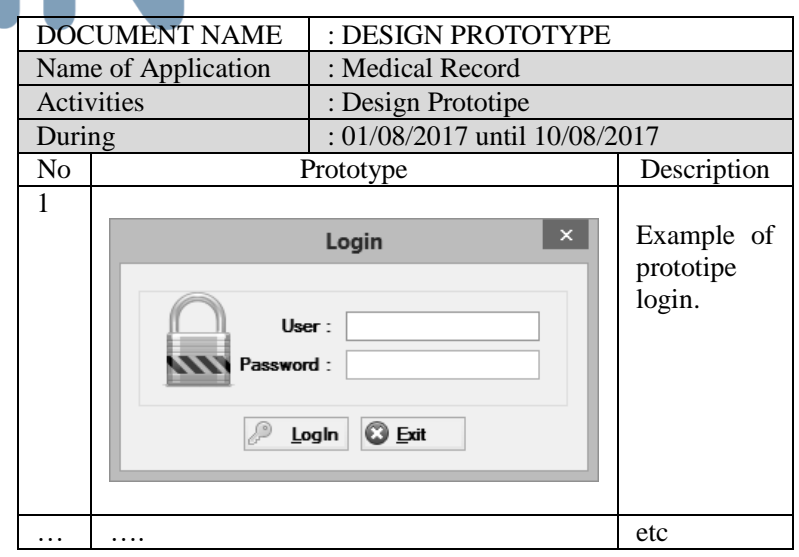

Fig 8. Mapping Prototype

Due to the limitations in this paper, only one sample of master physician prototype designs is shown. 


\section{G. Coding}

In the coding stage of the activities undertaken are: create a database and create programs. The following table mapping the needs of the tables used in the application, see Table 5.

Table 5. Mapping of tables in database

\begin{tabular}{|l|l|l|}
\hline No & \multicolumn{1}{|c|}{ Tabel Name } & \multicolumn{1}{c|}{ Description } \\
\hline 1 & tblSpecialist & To Save data spesialis \\
\hline 2 & tblDoctor & To Save data doctor \\
\hline 3 & tblPatient & To Save data patient \\
\hline 4 & tblDiagnosed & To Save data diagnosed \\
\hline 5 & tblClinicName & To Save data clinic \\
\hline 6 & tblDrug & To Save data drug \\
\hline 7 & tblUnit & To Save data unit \\
\hline 8 & tblTypeOfDrug & To Save data type of drug \\
\hline 9 & tblHRecipe & To Save data copy of recipe \\
\hline 10 & tblDRecipe & To Save data detail copy of recipe \\
\hline 11 & tblUser & To Save data user \\
\hline
\end{tabular}

The following table mapping user interface on the application, see table 6 . Include in mapping are form name and description, like: login, clinic name, user, recipe, Etc.

Table 6. Mapping userinterface

\begin{tabular}{|l|l|l|}
\hline No & \multicolumn{1}{|c|}{ Form Name } & \multicolumn{1}{|c|}{ Description } \\
\hline 1 & frmLogin & For login to application \\
\hline 2 & frmClinicName & For logs clinic Name \\
\hline 3 & frmSpecialist & For logs specialist \\
\hline 4 & frmDoctor & For logs doctor \\
\hline 5 & frmPatient & For logs patient \\
\hline 6 & frmTypeOfDrug & For logs type of drug \\
\hline 7 & frmUnit & For logs unit drug \\
\hline 8 & frmDrug & For logs drug \\
\hline 9 & frmUser & For logs user \\
\hline 10 & frmDiagnosed & For logs doctor of diagonose \\
\hline 11 & frmRecipe & For logs recipe \\
\hline 12 & frmRecapDoktor & For Print recap of doctor \\
\hline 13 & frmRecapThePatient & For Print recap of patient \\
\hline 14 & frmCost & For Print cost \\
\hline 15 & frmDoctorFee & For Print fee of doctor \\
\hline
\end{tabular}
Fig 9.

Here's the mapped design table documentation, see

\begin{tabular}{|c|c|c|c|c|c|}
\hline \multicolumn{3}{|c|}{ DOCUMENT NAME } & \multicolumn{3}{|c|}{ : DESIGN TABEL } \\
\hline \multicolumn{3}{|c|}{ Name of Application } & \multicolumn{3}{|c|}{ : Medical Record } \\
\hline \multicolumn{3}{|c|}{ Activities } & \multicolumn{3}{|c|}{ : Design tabel } \\
\hline \multicolumn{3}{|c|}{ During } & \multicolumn{3}{|c|}{ : 21/08/2017 until $05 / 09 / 2017$} \\
\hline No & & & Table & & Description \\
\hline \multirow{4}{*}{$\begin{array}{l}\text { No } \\
1\end{array}$} & \multicolumn{4}{|c|}{ tblSpecialist } & \multirow{4}{*}{$\begin{array}{l}\text { Example } \\
\text { table } \\
\text { spesialist. }\end{array}$} \\
\hline & \multirow{3}{*}{8} & Field Name & \multirow{2}{*}{$\begin{array}{l}\text { Data Type } \\
\text { Text }\end{array}$} & \multirow[b]{2}{*}{ Field Size $=3$} & \\
\hline & & IdSpecialist & & & \\
\hline & & Specialist & Text & Field Size $=30$ & \\
\hline \multirow[t]{11}{*}{2} & \multicolumn{4}{|c|}{ tolDoctor } & \multirow{11}{*}{$\begin{array}{l}\text { Example of } \\
\text { table doctor. }\end{array}$} \\
\hline & & Field Name & \multicolumn{2}{|l|}{ Data Type } & \\
\hline & & DateofBirth & \multicolumn{2}{|l|}{ Date/Time } & \\
\hline & & PlaceofBirth & Text & Fiedl Size $=30$ & \\
\hline & & Sex & Text & Fiedl Size $=10$ & \\
\hline & & CardNumber & Text & Fiedl Size $=30$ & \\
\hline & & PhoneNumber & Text & Fiedl Size $=15$ & \\
\hline & & Address & Memo & & \\
\hline & & Active & Text & Fiedl Size = 5 & \\
\hline & & DoctorFees & Number & & \\
\hline & & Photo & Memo & & \\
\hline$\ldots$ & $\ldots$ & & & & etc \\
\hline
\end{tabular}

Fig 9. Documentation Table

Here is the documentation of making the coding that has been mapped on the user interface, see Fig 10.

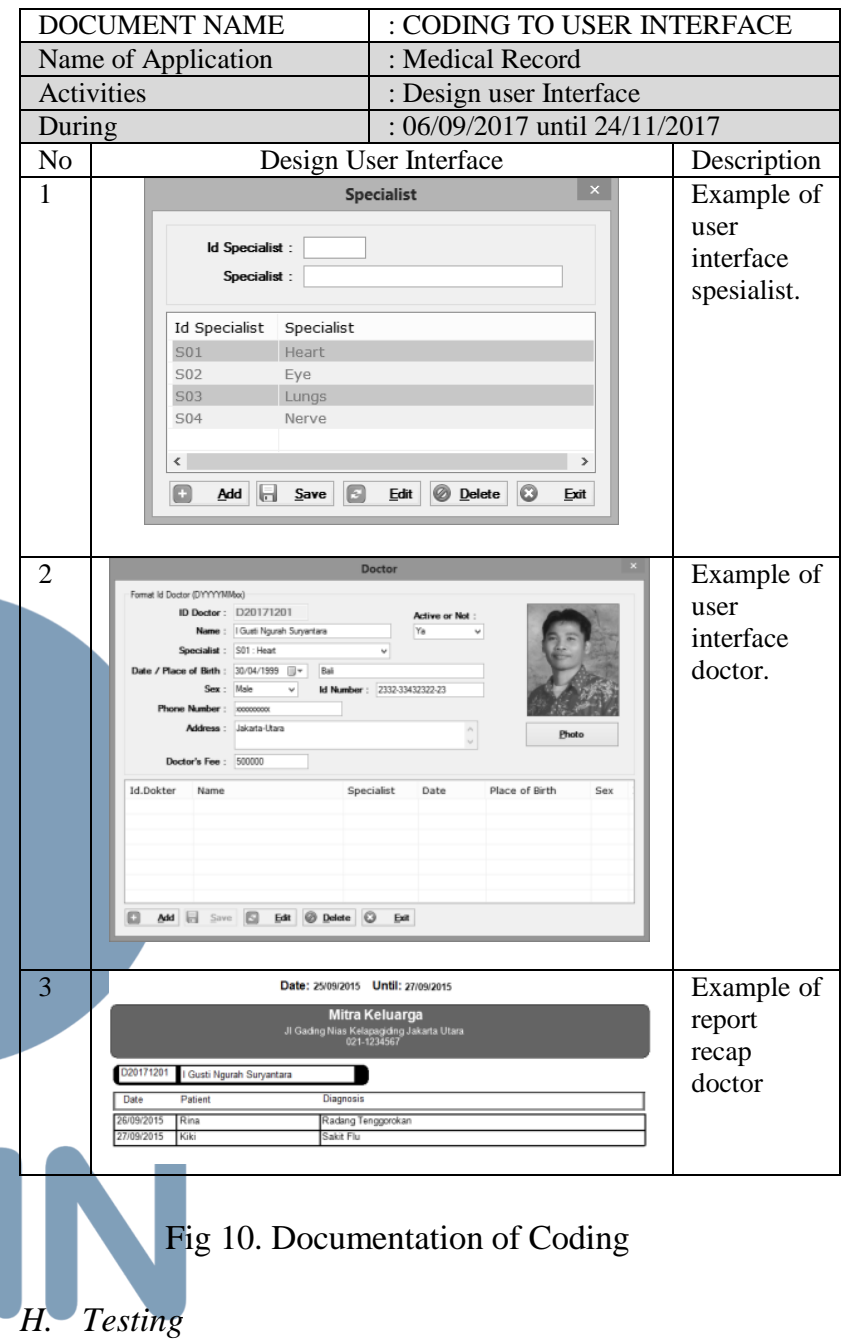

In XP, testing with white box on each module is done simultaneously when creating the program, each module is completed directly made white box testing. Here are the mapping of test results of each module, see table 7. Due to the limitations in this paper, there are only a few examples of table design and user interface.

Table 7. Mapping result of testing with white box

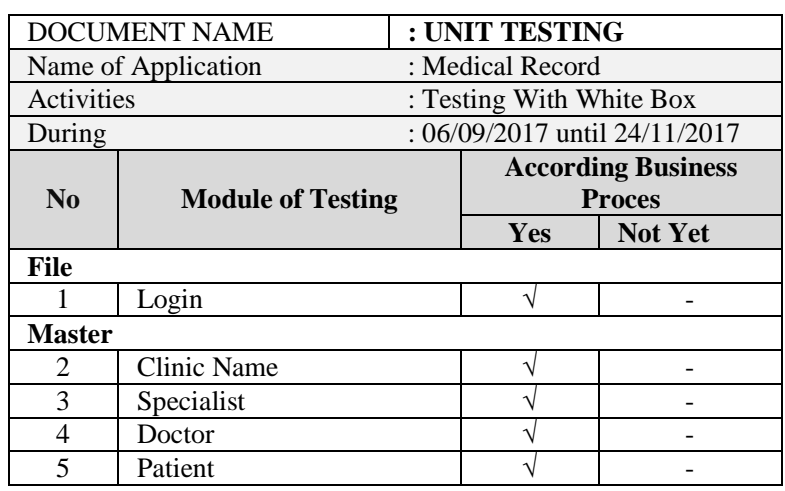




\begin{tabular}{|c|l|c|c|}
\hline 6 & Type of Drug & $\sqrt{ }$ & - \\
\hline 7 & Unit & $\sqrt{ }$ & - \\
\hline 8 & Drug & $\sqrt{ }$ & - \\
\hline 9 & User & $\sqrt{ }$ & - \\
\hline \multicolumn{3}{|l|}{ Transaction } \\
\hline 10 & Diagnosed & $\sqrt{ }$ & - \\
\hline 11 & Recipe & $\sqrt{ }$ & - \\
\hline Report & Recap Doctor & $\sqrt{ }$ & - \\
\hline 12 & Rer & $\sqrt{ }$ & - \\
\hline 13 & Recap the Patient & $\sqrt{ }$ & - \\
\hline 14 & Cost & $\sqrt{ }$ & - \\
\hline 15 & Doctor's Fee & &
\end{tabular}

Table 8. Mapping result testing with black box

\begin{tabular}{|c|c|c|c|}
\hline \multicolumn{2}{|c|}{ DOCUMENT NAME } & \multicolumn{2}{|c|}{ : UNIT TESTING } \\
\hline \multicolumn{2}{|c|}{ Name of Application } & \multicolumn{2}{|c|}{ : Medical Record } \\
\hline \multicolumn{2}{|c|}{ Activities } & \multicolumn{2}{|c|}{ : Testing With Black Box } \\
\hline \multicolumn{2}{|c|}{ During } & \multicolumn{2}{|c|}{$: 25 / 11 / 2017$ until $30 / 11 / 2017$} \\
\hline \multirow[t]{2}{*}{ No } & \multirow[t]{2}{*}{ Module of Testing } & \multicolumn{2}{|c|}{$\begin{array}{c}\text { According Business } \\
\text { Process }\end{array}$} \\
\hline & & Yes & Yes \\
\hline \multicolumn{4}{|l|}{ File } \\
\hline 1 & Login & $\sqrt{ }$ & - \\
\hline \multicolumn{4}{|c|}{ Master } \\
\hline 2 & Clinic Name & $\sqrt{ }$ & - \\
\hline 3 & Specialist & $\sqrt{ }$ & - \\
\hline 4 & Doctor & $\sqrt{ }$ & - \\
\hline 5 & Patient & $\sqrt{ }$ & - \\
\hline 6 & Type of Drug & $\sqrt{ }$ & - \\
\hline 7 & Unit & $\sqrt{ }$ & - \\
\hline 8 & Drug & $\sqrt{ }$ & - \\
\hline 9 & User & $\sqrt{ }$ & - \\
\hline \multicolumn{4}{|c|}{ Trasaction } \\
\hline 10 & Diagnosed & $\sqrt{ }$ & - \\
\hline 11 & Recipe & $\sqrt{ }$ & - \\
\hline \multicolumn{4}{|c|}{ Report } \\
\hline 12 & Recap Doctor & $\sqrt{ }$ & - \\
\hline 13 & Recap the Patient & $\sqrt{ }$ & - \\
\hline 14 & Cost & $\sqrt{ }$ & $=$ \\
\hline 15 & Doctor's Fee & $\sqrt{ }$ & \\
\hline
\end{tabular}

Testing is the process of running or executing a program with the main purpose of finding errors [23]. Testing is done to identify and identify possible errors [24]. Application Test with black box done by client in this case user. Table 8 can show mapping result testing with black box.

\section{Software Increment}

Software Increment is the stage for releasing applications that have been created with the XP framework.

\section{CONCLUSION}

The purpose of the system development framework is to get a life cycle and blueprint of system development, XP is well used in the development of object-oriented systems. The XP framework provides changes to system development according to the needs of the user at any time during the application development phase, so that the user's need for an apps that suits their needs is greatly accommodated. With the XP framework that every step always involves users, programmers, and parts of testing so that the applications created can be completed in a timely manner and in accordance with the needs of users. Applications created in this study using the XP framework, is a medical record application that is tested in black box to complete the computerized application of clinic include: data collection master, transaction data, and generate reports.

At the time of application development with the XP framework must involve from the user, so that each system module made more suitable to the needs of the user to minimize misperception between the user and the application creator. Within the framework with XP it places great emphasis on the program, so CRC makers must be thorough and consider the interconnectedness of CRCs with each other.

\section{REFERENCES}

[1] A. Hameed, "Software Development Lifecycle for Extreme Programming," International Journal of Information Technology and Electrical Engineering, Volume 5, Issue 1, ISSN: - 2306-708X, 2016.

[2] Systems Development Lifecycle, Objectives and Requirements. Bender RPT Inc, 2003.

[3] O. Nikiforova, V. Nikulsins, U. Sukovskis, "Integration of MDA Framework into the Model of Traditional Software Development," Frontiers in Artificial Intelligence and Applications, Databases and Information Systems, Vol. 187, pp. 229-239. IOS Press, Amsterdam, 2009.

[4] G. DeHondt II, A. Brandyberry, "Programming in the eXtreme: Critical Characteristics of Agile Implementations," e-Informatica Software Engineering Journal, Volume 1, Issue $1,2007$.

[5] I.G.N. Suryantara, "Merancang Aplikasi Dengan VB.Net 2013," Elex Media Komputindo. Jakarta, 2014.

[6] https://medium.com/agility-path/5-reasons-why-extremeprogramming-isnt-popular-83790418b901, access date May 13,2018

7] K. Surendro, "Pengembangan Perancangan Induk Sistem Informasi," Penerbit Informatika. Bandung, 2009.

8] J. Highsmith, "Cutter Consortium Reports: Agile Project Management: Principles and Tools,"Volume 4(2), Cutter Consortium, Arlington, MA, 2003.

[9] J. Highsmith, “ Agile Software Development Ecosystems," Addison-Wesley, Boston, MA, 2002.

[10] I.G.N. Suryantara, "Merancang Aplikasi Dengan Metodologi Extreme Programming," Elex Media Komputindo, Jakarta, 2017.

[11] I.G.N. Suryantara, "Merancang Aplikasi Rekam Medis Dengan VB.Net," Elex Media Komputindo, Jakarta, 2015.

[12] M. Hneif and S. H. Ow, "Review Of Agile Methodologies In Software Development," International Journal of Research and Reviews in Applied Sciences, Volume 1, Issue 1, ISSN: 2076-734X, EISSN: 2076-7366, 2009.

[13] D. Karlström, "Introducing Extreme Programming - An Experience Report," Proceedings 3rd International Conference on eXtreme Programming and Agile Processes in Software Engineering XP, Sardinia, Italy, 2002.

[14] C. Schwaber and R. Fichera, "Corporate IT leads the second wave of agile adoption," Forrester Research, Inc, 2005.

[15] N. Kumar, A. S. Zadgaonkar, A. Shukla, "Evolving a New Software Development Life Cycle Model SDLC-2013 with Client Satisfaction," International Journal of Soft Computing and Engineering (IJSCE), ISSN: 2231-2307, Volume-3, Issue-1, 2013.

[16] Software Development Life Cycle (SDLC) - the five common principles.htm 


\section{ISSN 2355-0082}

[17] Software Methodologies Advantages \& disadvantages of various SDLC models.mht

[18] M. Raza, "Good Medical Record Keeping," International Journal of Collaborative Research on Internal Medicine \& Public Health, Vol. 4 No. 5, 2012.

[19] B. A. AL-nassar, M. S. Abdullah and W.R.S Osman, "Healthcare Professionals use Electronic Medical Records System (EMRs) in Jordan Hospitals," IJCSNS International Journal of Computer Science and Network Security, Vol.11, No.8, 2011.

[20] A. Brookstone, "Electronic medical records: Creating the environment for change," british columbia medical journal, vol. 46, pp. 233-235, 2004.
[21] G. Tevaarwerk, "Electronic medical records,"Canadian Medical Association Journal, vol. 178, p.1323, 2008

[22] R. LeBlond, R. DeGowin, and D. Brown, "Electronic Medical Records," McGraw-Hill's AccessMedicine, 2009.

[23] G. Saini, and K. Rai, "An Analysis on Objectives, Importance and Types of Software Testing," International Journal of Computer Science and Mobile Computing, Vol. 2, no. 9, 18$23,2013$.

[24] J. F. Andry, "Pengembangan Aplikasi Backup Dan Restore Secara Automatisasi Menggunakan SDLC Untuk Mencegah Bencana," Jurnal Muara Sains, Teknologi, Kedokteran, dan Ilmu Kesehatan, 1(1), 29-38, 017.

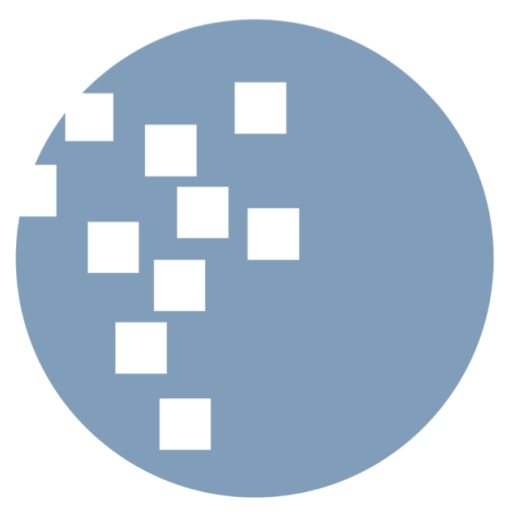

